\title{
Counselling and support services for civil emergencies and major incidents
}

\author{
Psychodynamic reflections
}

\author{
Anne Nightingale, George Smith and David Scott
}

\begin{abstract}
Across the UK counselling and support services are belng developed as on extension of emergency planning for major incidents, with the aim of offering poychological help in the immediate affermath of a disaster. In Strathclyde, Social Work and Mental Health Services Jolntty established Laison Teams with the task of planning and preparing for a major incident. We describe the response of a Liatson Team to a serlous bus accident and present reflections from a poychodynamic perspective on some of the factors which may bear on planning and dellvery of services.
\end{abstract}

\section{Major incident, September 1994}

The Liaison Team met following a bus crash in Glasgow which resulted in fatalities and serious injuries among a group of children and adults from the Drumchapel area of the city returning from a day trip.

Rather than immediately offering counselling as a direct service to those affected, senior professional staff from the Liaison Team met with representatives of the Drumchapel community who were already in touch with the bereaved families. These individuals, known and respected locally, included members of the clergy. teachers, community leaders and members of local voluntary organisations. Through discussion it was agreed that the statutory services should be available to offer direct support, but would in the first instance stand in support of those to whom the bereaved had already turned as soon as the accident occurred. It was decided that this back-up support would be provided by the existing statutory services rather than the counselling staff from the Liaison Team who would have had limited knowledge of the local community and its resources.

A range of services was organised in response to the major incident, including practical assistance of various kinds, a telephone helpline and a letter offering support sent to all the families involved. Senior staff from the Liaison Team met regularly with the representatives from the community, the emergency services and the local statutory services for four weeks. This was to monitor and coordinate events and to provide a setting where reflection could occur. The meetings provided a forum in which a range of practical issues, anxieties and questions could be raised, both on behalf of those affected by the accident and by the individuals offering support.

For some of these matters there were practical solutions, for others there were not, but the meetings allowed discussion and joint attempts to 'think through' the possibilities. As a result there was ready communication between the different agencies involved and very little of the misunderstanding, duplication of initiatives or confusion which has sometimes bedevilled attempts at interagency cooperation following disasters.

This approach was based on the principle that individuals, families and communities have inherent strengths which are especially needed at times of crisis, and that it would be wrong for statutory agencies to dismiss these and develop responses without assistance and coordination at a local level.

\section{Some reflections on disaster counselling}

The last few years have seen the rapid development throughout the UK of counselling services whose remit is to provide psychological support in the aftermath of disasters. There is an important political dimension to this development, both in terms of the initiatives involved and in terms of the expectations and reactions of the wider community in the face of a large-scale, often horrifying. disaster. It is commonplace nowadays that after a news report of a particularly distressing incident. the listening/watching public are told that the 
survivors/relatives will be seen by "trained counsellors', often with the implication that this is to occur within hours of the incident. However, the evidence that very early psychological intervention is protective against the later development of psychological sequelae is not compelling, and the literature contains studies which demonstrate no beneficial impact on later psychiatric morbidity from interventions such as psychological debriefing (Deahl et al, 1994; Hobbs et al, 1996).

A recent editorial by Raphael et al (1995) entitled 'Does debriefing after trauma work?' states that "there is a dearth of systematic evaluation and outcome studies" concerning debriefing, and that there have been "no adequate demonstrations of beneficial effects or prevention of post-traumatic morbidity". Raphael et al even go so far as to say "the possibility that debriefing may increase problems warrants further consideration".

\section{A psychodynamic perspective on the nature and location of the 'need' by which a major incident counselling service is 'led'}

The drive to develop major incident counselling services appears to stem from a widely held notion that the early provision of counselling or psychological debriefing for disaster victims/ survivors is 'a good idea'. To question this can invite the angry accusation that one does not care' about those who have been struck by tragedy. This gives a clue to the possibility that emotional forces may be impinging on service planning. It may be that different qualities of need are aroused in different people; for example, the needs of the disaster survivors themselves may differ from those of members of the wider society, personified by the trained counsellors' of the news bulletin. A question arises: is the need to offer counselling a relevant factor, and if so, upon what is it based and what are its likely consequences?

\section{The need to help}

In psychodynamic psychotherapy a consideration of the therapist's contribution to the therapeutic relationship is a normal part of the unfolding therapeutic process. At times the possibility has to be considered that the therapist's need (to help, to be needed, to locate illness outside him/herself, etc.) is playing its part. Such phenomena occur widely in human relationships but perhaps particularly in the field of 'disaster counselling' where, by its very nature, the occurrence of the disaster evokes the highest levels of emotional arousal. Panicky feelings in the helpers, a sense of emergency, desperation, terror and helplessness are the norm in this kind of situation. Our hypothesis is that the overwhelming nature of the anxiety aroused by a disaster evokes powerful emotional reactions in the helpers with implications for the fulfilment of their task.

\section{The importance of a fantasy of rescue}

Human beings faced with a reality of extreme helplessness may react in a number of ways, for example with despair, helplessness or emotional dissociation. Another response is to turn the psychological experience of helplessness into its opposite - omnipotence. Under the emergency conditions of a disaster, where disaster workers are likely to experience a powerful impulse to act, this omnipotence could take the form of a fantasy that rescue is possible, to the extent that what cannot be put right may be denied or ignored.

Such a coping mechanism (a rescue fantasy) could have a valuable function in some situations. For example, those dealing with the immediate physical reality of the disaster such as members of staff in police, fire, ambulance and casualty services might be assisted in their urgently necessary and difficult work by a capacity to invoke a rescue fantasy, especially if the magnitude of the disaster might otherwise overwhelm the capacity to sustain hope in action.

However, the situation is different for those whose task is to offer appropriate psychological help. Here, enactment by staff of a rescue fantasy with its inherent denial of psychic reality is unlikely to assist those who have been traumatised. The sense of urgency which tends to impel workers towards action needs to be thought through. It is likely to represent a powerful wish to help, based on an awareness of the emotional pain which the disaster has caused. But if the wish to respond to and relieve others' pain is translated without reflection into action, it can involve a denial of what cannot be repaired, and hence a denial of the very pain involved.

Facing up to this and attending to the ordinary human requirements of those affected is in our view a sound basis from which to coordinate and plan services. Inherent in this approach is a respect for the strengths and coping mechanisms of the individuals/families/communities involved. An urgent impulse to 'rush in' with counselling services in the immediate aftermath of a disaster may represent something to be reflected upon, rather than enacted.

\section{Implications for service provision}

Under the impact of the anxiety attendant on a major disaster, thinking may be one of the first casualties. One consequence is that, for staff whose task is to offer psychological support, there is a risk that action may precede thinking. This possibility can be predicted and needs to be taken into account in planning the structures 
through which psychological support may be offered.

Those who have survived a disaster may find themselves the focus for the enactment of others' rescue fantasies. If this occurs in the psychological sphere a secondary traumatisation may occur, with the disaster survivor having to contend not simply with his/her own traumatic experience, but with the emotional needs of the helpers.

Bearing this in mind, it becomes particularly important to ensure that psychological support services should be based as far as possible on the actual communicated needs of the survivors, rather than on the needs of the wider society, expressed through the helping agencies, to 'do something' or 'to help'. This will entail paying careful attention to the situation that has arisen and to the priorities, expectations and wishes of those who have been affected.

\section{Acknowledgements}

With thanks to Dr Anne Tait and to an anonymous reviewer for helpful comments on an earlier draft of this paper.

\section{References}

Deahl, M. P., Gillham, A. B., Thomas, J., et al (1994) Psychological sequelae following the Gulf War. Factors associated with subsequent morbidity and the effectiveness of psychological debriefing. British Joumal of Psychiatry. 165, 60-65.

HOBBS, M., MAYOU, R. HARRISON, B., et al (1996) A randomised controlled trial of psychological debriefing for victims of road traffic accidents. Britlsh Medical Journal, 313, 1438-1439.

RapHaEl, B., Meldrum, L. \& McFariane, A. L. (1995) Does debriefing after psychological trauma work? British Medical Journal, 310, 1479-1480.

*Anne Nightingdale, Consultant Psychotherapist, Lansdowne Clinic, 3 Whittingehame Gardens, Glasgow G12 OAA; George Smith, Assistant District Manager, North-West District Social Work Department, 59 Ruchill Street, Glasgow; and David Scott, Consultant Clinical Psychologist/ Psychotherapist, Lansdowne Clinic, Whittingehame Gardens, Glasgow G12 OAA

*Correspondence 